\title{
Investigação molecular de Ehrlichia canis, Anaplasma platys, Anaplasma phagocytophilum e Rickettsia spp. em felídeos selvagens cativos ${ }^{1}$
}

Giovana A. Mazzotti ${ }^{2}$, Wanessa A.C. Silva², Filipe T. Carneiro ${ }^{2}$, Marcela C. Scalon ${ }^{2}$, Mariana A. Lima², Marianne A. Teixeira², Alice C.F. Lima² e Giane R. Paludo ${ }^{2 *}$

\begin{abstract}
Mazzotti G.A., Silva W.A.C., Carneiro F.T., Scalon M.C., Lima M.A., Teixeira M.A., Lima A.C.F. \& Paludo G.R. 2018. [Molecular investigation of Ehrlichia canis, Anaplasma platys, Anaplasma phagocytophilum and Rickettsia spp. in captive wild felids.] Investigação molecular de Ehrlichia canis, Anaplasma platys, Anaplasma phagocytophilum e Rickettsia spp. em felídeos selvagens cativos. Pesquisa Veterinária Brasileira 38(3):528-535. Laboratório de Patologia Clínica Veterinária, Faculdade de Agronomia e Medicina Veterinária, Universidade de Brasília, SGAN 605, Avenida L2, Brasília, DF 70910-900, Brazil. E-mail: giane@unb.br

Vector-borne diseases have been emerging and reemerging all over the world, causing a challenge to veterinary and human medicine. Among these diseases are those caused by agents of the order Rickettsiales, obligatory intracellular Gram-negative bacteria, with ability to infect several animals and humans. Rickettsiales of the species Ehrlichia spp. and Anaplasma spp. residing in cytoplasmic vacuoles of leukocytes and platelets. Rickettsiales of the species Rickettsia spp. freely infect cytoplasm or nucleus of host cells. The aim of the present study was to investigate the natural infection with Ehrlichia canis, Anaplasma platys, Anaplasma phagocytophilum and Rickettsia spp. in captive wild felids at the Federal District and Goiás, Brazil. In addition, it was also aimed to relate possible changes in hemogram with the presence of these agents. Blood samples from 34 animals were analyzed by PCR to detect the presence of DNA from these agents. The DNA of Ehrlichia canis was detected in $5.8 \%(2 / 34)$ of samples. A. platys was detected in $64.7 \%(22 / 34)$, A. phagocytophilum was detected in 5.8\% (2/34). The DNA of Rickettsia spp. was not detected in any sample. Two felides presented co-infection with E. canis and A. platys, and two presented co-infection with A. platys and A. phagocytophilum. There were no significant differences in hematological data from positive and negative samples. The data suggest that captive wild felids can serve as potential reservoirs for Ehrlichia spp. and Anaplasma spp., despite hematological abnormalities were not observed.

INDEX TERMS: Molecular investigation, Ehrlichia canis, Anaplasma platys, Anaplasma phagocytophilum, captivity, wild felids, Anaplasma spp., diagnose, polymerase chain reaction, cats, parasitoses.
\end{abstract}

RESUMO.- Doenças transmitidas por vetores estão emergindo e reemergindo em todo o mundo, representando um desafio na medicina humana e veterinária. Entre essas doenças estão aquelas causadas pelos agentes da ordem das Rickettsiales, que são bactérias Gram-negativas intracelulares obrigatórias, com capacidade de infectar vários animais e seres humanos.

\footnotetext{
${ }^{1}$ Recebido em 5 de julho de 2017.

Aceito para publicação em 16 de agosto de 2017.

${ }^{2}$ Laboratório de Patologia Clínica Veterinária, Faculdade de Agronomia e Medicina Veterinária, Universidade de Brasília (UnB), SGAN 605, Avenida L2, Brasília, DF 70910-900, Brasil. *Autor para correspondência: giane@unb.br
}

As Rickettsiales das espécies Ehrlichia spp. e Anaplasma spp. são observadas em vacúolos citoplasmáticos de leucócitos e plaquetas. As Rickettsiales da espécie Rickettsia spp. infectam livremente citoplasma ou núcleo de células hospedeiras. 0 objetivo do presente estudo foi investigar a infecção natural por Ehrlichia canis, Anaplasma platys, Anaplasma phagocytophilum e Rickettsia spp. em felídeos selvagens cativos no Distrito Federal e Goiás, Brasil. Além disso, também objetivou-se relacionar possíveis alterações hematológicas decorrentes da presença desses agentes. Amostras de sangue de 34 animais foram analisadas por meio da PCR para detecção de presença de DNA desses agentes. O DNA de Ehrlichia canis foi detectado 
em 5,8\% (2/34) das amostras, $A$. platys foi detectado $64,7 \%$ (22/34), A. phagocytophilum foi detectado em 5,8\%(2/34). O DNA de Rickettsia spp. não foi detectado em nenhuma amostra. Dois felídeos apresentaram coinfecção por E. canis e A. platys e dois apresentaram coinfecção por A. platys e A. phagocytophilum. Não houve diferenças significativas nos dados hematológicos das amostras positivas e negativas. Os dados sugerem que os felídeos selvagens cativos podem servir como potenciais reservatórios para Ehrlichia spp. e Anaplasma spp., a despeito de não ocasionarem alterações hematológicas.

TERMOS DE INDEXAÇÃO: Investigação molecular, Ehrlichia canis, Anaplasma platys, Anaplasma phagocytophilum, Rickettsia spp., felídeos selvagens, cativeiro, Anaplasma spp., diagnóstico, PCR, felinos, parasitoses.

\section{INTRODUÇÃO}

A ordem Rickettsiales, composta pelas famílias Rickettsiaceae e Anaplasmataceae, compreende bactérias Gram-negativas intracelulares obrigatórias, muito pequenas $(0,3$ a 2,0 $\mu \mathrm{m})$, pleomórficas, sem motilidade (Dumler et al. 2001, Fournier \& Raoult 2007). Algumas dessas bactérias podem causar danos à saúde tanto dos animais quanto de seres humanos infectados (Vieira et al. 2011). As bactérias Rickettsia rickettsii, R. parkeri, Rickettsia sp. cepa Mata Atlântica são consideradas importantes zoonoses (Soares et al. 2015, Oliveira et al. 2017), bem como o Anaplasma phagocytophilum, Ehrlichia chaffeensis e E. ewingii (Vieira et al. 2011).

Já foi relatada a ocorrência de nove agentes da família Rickettsiaceae no Brasil. As espécies que têm como vetores os carrapatos pertencem aos grupos Febre Maculosa (R. rickettsii, $R$. parkeri, $R$. rhipicephali e candidatus "R. amblyommii") e belli ( $R$. bellii). As espécies transmitidas por pulgas pertencem ao grupo de transição ( $R$. felis); Grupo do tifo ( $R$. typhi) e Grupo Canadensis (R. monteiroi) (Almeida et al. 2011, Labruna et al. 2011). As cepas de rickettsias já descritas foram Mata Atlântica (ou Bahia), ApPR, COOPERI, NOD, Aranha e Pampulha (Parola et al. 2013). A família Anaplasmataceae compreende os gêneros Anaplasma, Ehrlichia e Neorickettsia (Dumler et al. 2001). No Brasil, já foram encontradas as espécies A. platys, A. phagocytophilum, A. bovis (Sacchi et al. 2012), A. marginale (Picoloto et al. 2010), E. canis, E. chaffeensis e E. ewingii, todas tendo como vetor o carrapato (Vieira et al. 2011). A espécie $N$. risticii, descrita infectando equinos no Rio Grande do Sul, tem como vetores trematódeos aquáticos (Coimbra et al. 2006).

Poucos trabalhos descreveram a ocorrência desses agentes em felídeos silvestres no país (Filoni et al. 2006, André et al. 2010, 2012, Widmer et al. 2011). No Brasil, Filoni et al. (2006) realizaram o primeiro trabalho buscando a presença de anticorpos para E. canis e A. phagocytophilum em amostras de sangue de 21 felídeos silvestres (18 pumas, 2 gatos do mato e 1 jaguatirica) de vida livre provenientes dos biomas Floresta Amazônica, Floresta Atlântica, cerrado e Pantanal. Utilizou-se a técnica de imunofluorescência indireta (IFA), obtendo-se $5 \%$ das amostras positivas para E. canis (1 puma) e nenhuma para A. phagocytophilum. Em 2010, André et al. desenvolveram um trabalho mais amplo, utilizando além da
IFA, a técnica de reação em cadeia pela polimerase (PCR) para identificar a presença de DNA de E. canis em amostras de sangue de 72 animais (29 jaguatiricas, 14 gatos do mato, 9 onças, 9 pumas, 6 jaguarundi, 3 gatos dos pampas, e 2 gatos maracajá) mantidos em cativeiro, provenientes do estado de São Paulo e de Brasília. Esse estudo resultou em de $7 \%$ das amostras positivas na IFA e 15\% positivos na PCR. Widmer et al. (2011) pesquisaram anticorpos (IFA) e DNA (PCR) de agentes Rickettsiales em amostras de sangue de 10 onças de vida livre provenientes do Pantanal, não encontrando nenhuma amostra positiva pela PCR, entretanto, $40 \%$ foram positivos para $E$. canis e $10 \%$ para $R$. parkeri pela IFA. Em 2012, André et al. analisaram amostras de sangue de 99 felídeos cativos, provenientes do estado de São Paulo e Mato Grosso, dos quais 21\% foram positivos pela PCR para Ehrlichia spp. (6 gatos do mato, 4 jaguatiricas, 4 pumas, 3 jaguarundis, 3 leões e 1 tigre), sendo 11 amostras semelhantes a E. chaffenesis e 10 semelhantes a E. canis, quando analisadas pelo BLAST. Também foram encontrados DNA de Anaplasma spp. em 4\% das amostras (4 gatos do mato), sendo semelhante a A. phagocytophilum pelo BLAST. Até o presente, nenhum autor relacionou a presença desses agentes as alterações hematológicas de felídeos silvestres mantidos em cativeiro.

Esse trabalho teve como objetivo investigar a ocorrência de infecção natural por E. canis, A. platys, A. phagocytophilum e Rickettsia spp. em felídeos selvagens cativos no Distrito Federal e Goiás, Brasil, utilizando o método de reação em cadeia pela polimerase (PCR) para detecção do DNA desses agentes em amostras de sangue total e as possíveis alterações hematológicas decorrentes destas infecções.

\section{MATERIAL E MÉTODOS}

O estudo teve autorização da Comissão de Ética para Uso Animal da Universidade de Brasília (CEUA- UnB) (UnB-DOC no 130988/2015) e do Instituto Brasileiro do Meio Ambiente e Recursos Naturais (IBAMA) (SISBIO nำ46097).

Amostras de sangue foram coletadas de 34 felídeos cativos, sem alterações clínicas aparentes, albergados no zoológico de Brasília, Distrito Federal (Zoo) e em um Centro Conservacionista de animais selvagens localizado no estado de Goiás (CC).

Os animais foram anestesiados utilizando-se dardos com anestésico tiletamina com zolazepam lançados por zarabatana na dose de 1,6 a 4,2mg/kg para grandes felinos, e até $11 \mathrm{mg} / \mathrm{kg}$ para os pequenos felinos (Larsen et al. 2008). Foram coletados $5 \mathrm{ml}$ de sangue de cada animal utilizando-se seringas e agulhas descartáveis e acondicionados em tubos com EDTA, identificados e refrigerados para posterior análise laboratorial.

Para determinar o número de hemácias, leucócitos, plaquetas e a concentração de hemoglobina utilizou-se um contador hematológico veterinário semiautomático (Vet abc, HORIBA ${ }^{\circledR}$ Instruments Brasil Ltda, São Paulo, Brasil). O volume globular (VG) foi determinado utilizando a técnica de micro-hematócrito. A contagem diferencial de leucócitos e a avaliação morfológica celular foram realizadas manualmente por meio da microscopia óptica a partir de esfregaços sanguíneos corados com panótico (Panótico NewProv ${ }^{\circledR}$, Barueri, São Paulo, Brasil). Esse processo foi realizado no Laboratório de Patologia Clínica do Hospital Veterinário da UnB. 
Armazenou-se uma parte de cada amostra de sangue a $4^{\circ} \mathrm{C}$ até à extração de DNA, que foi realizada utilizando kit comercial (Illustra Blood ${ }^{\circledR}$ genomicPrep Mini Spin kit, GE Healthcare Technologies, Piscataway, NJ) de acordo com as instruções do fabricante. 0 DNA obtido foi armazenado a $-20^{\circ} \mathrm{C}$ para posterior análise pela PCR. A extração de DNA e a PCR foram realizadas no Laboratório de Microbiologia e Patologia Molecular do Hospital Veterinário da UnB.

Todas as amostras foram submetidas à PCR para confirmação da presença do gene que codifica a enzima gliceraldeído-3fosfato desidrogenase (GAPDH) utilizando os oligonucleotídeos GAPDH-F e GAPDH-R (Birkenheuer et al. 2003) para verificar a qualidade da extração, a integridade do DNA obtido e/ou a presença de inibidores da PCR. A mistura da PCR foi composta de tampão 1X, 10ng de DNA, $\mathrm{MgCl}_{2} 1,5 \mathrm{mM}, 0,2 \mathrm{mM}$ de cada deoxinucleotídeo (Invitrogen ${ }^{\circledR}$ Brasil Ltda, São Paulo, Brasil), $1 \mu \mathrm{L}$ de cada oligonucleotídeo a $10 \mathrm{pmol}$ e 1,25U de Taq DNA polimerase (Invitrogen ${ }^{\circledR}$ Brasil Ltda, São Paulo, Brasil), para um volume final de $25 \mu \mathrm{L}$. 0 protocolo de amplificação foi composto de uma etapa de desnaturação inicial de $95^{\circ} \mathrm{C}$ por 5 minutos seguida de 40 ciclos de amplificação $\left(94^{\circ} \mathrm{C}\right.$ por 30 segundos, $52^{\circ} \mathrm{C}$ por 1 minuto e $72^{\circ} \mathrm{C}$ por 1 minuto) e extensão final a $72^{\circ} \mathrm{C}$ por 5 minutos.

Para detecção do DNA de agentes da família Rickettsiaceae foram utilizados os oligonucleotídeos CS78 e CS323 (Labruna et al. 2004). A mistura da PCR foi composta de tampão $1 X$ já acrescido de $\mathrm{MgCl}_{2}$ a 1,5mM (Promega Corporation ${ }^{\circledR}$, WI EUA), 10ng de DNA, $0,2 \mathrm{mM}$ de cada deoxinucleotídeo (Invitrogen ${ }^{\circledR}$ Brasil Ltda, São Paulo, Brasil), $1 \mu \mathrm{L}$ de cada oligonucleotídeo a 10 pmol e 1,25U de Taq DNA polimerase (Promega Corporation ${ }^{\circledR}$, WI EUA), para um volume final de $25 \mu \mathrm{L}$. 0 protocolo de amplificação foi composto de uma etapa de desnaturação inicial de $94^{\circ} \mathrm{C}$ por 5 minutos seguida de 40 ciclos de amplificação $\left(94^{\circ} \mathrm{C}\right.$ por 1 minuto, $56^{\circ} \mathrm{C}$ por 1 minuto e $72^{\circ} \mathrm{C}$ por 1 minuto) e extensão final a $72^{\circ} \mathrm{C}$ por 5 minutos.

Para a PCR que detectou o DNA de E. canis utilizou-se os oligonucleotídeos ECAN5 e HE3 (Murphy et al. 1998). A mistura da PCR foi composta de tampão $1 \mathrm{X}, \mathrm{MgCl}_{2}$ a $2 \mathrm{mM}$ (GE Health Care ${ }^{\circledR}$, Little Chalfont, UK), 10ng de DNA, 0,2mM de cada deoxinucleotídeo (Invitrogen ${ }^{\circledR}$ Brasil Ltda, São Paulo, Brasil), $3 \mu \mathrm{L}$ de cada oligonucleotídeo a $10 \mathrm{pmol}$ e 0,5U de Taq DNA polimerase (GE Health Care ${ }^{\circledR}$, Little Chalfont, UK), para um volume final de $25 \mu$ L. 0 protocolo de amplificação foi composto de uma etapa de desnaturação inicial de $94^{\circ} \mathrm{C}$ por 1 minuto seguida de 40 ciclos de amplificação $\left(94^{\circ} \mathrm{C}\right.$ por 1 minuto, $63^{\circ} \mathrm{C}$ por 2 minuto e $72^{\circ} \mathrm{C}$ por 90 segundos) e extensão final a $72^{\circ} \mathrm{C}$ por 5 minutos.

Na PCR para detecção do DNA de A. platys foram utilizados os oligonucleotídeos EHR16sr e Platys (Inokuma et al. 2000). A mistura da PCR foi composta de tampão 1X, 10ng de DNA, $\mathrm{MgCl}_{2}$ 3,2mM, 0,2mM de cada deoxinucleotídeo (Invitrogen ${ }^{\circledR}$ Brasil Ltda, São Paulo, Brasil), $3 \mu \mathrm{L}$ de cada oligonucleotídeo a 10 pmol e 1,25U de Taq DNA polimerase (Invitrogen ${ }^{\circledR}$ Brasil Ltda, São Paulo, Brasil), para um volume final de $25 \mu \mathrm{L}$. 0 protocolo de amplificação foi composto de uma etapa de desnaturação inicial de $95^{\circ} \mathrm{C}$ por 5 minutos seguida de 40 ciclos de amplificação $\left(95^{\circ} \mathrm{C}\right.$ por 30 segundos, $51^{\circ} \mathrm{C}$ por 30 segundos e $72^{\circ} \mathrm{C}$ por 90 segundos) e extensão final a $72^{\circ} \mathrm{C}$ por 5 minutos.

Para detecção do DNA de A. phagocytophilum utilizou-se os oligonucleotídeos MSP3F e MSP3R (Levin et al. 2002). A mistura da PCR foi composta de tampão $1 \mathrm{X}$ já acrescido de $\mathrm{MgCl}_{2}$ a 1,5mM (Promega Corporation ${ }^{\circledR}$, WI EUA), 10ng de DNA, 0,2mM de cada deoxinucleotídeo (Invitrogen ${ }^{\circledR}$ Brasil Ltda, São Paulo, Brasil), $1 \mu \mathrm{L}$ de cada oligonucleotídeo a 10pmol e 1,25U de Taq DNA polimerase (Promega Corporation ${ }^{\circledR}$, WI EUA), para um volume final de $25 \mu \mathrm{L}$. 0 protocolo de amplificação foi composto de uma etapa de desnaturação inicial de $94^{\circ} \mathrm{C}$ por 5 minutos seguida de 40 ciclos de amplificação $\left(94^{\circ} \mathrm{C}\right.$ por 1 minuto, $61^{\circ} \mathrm{C}$ por 1 minuto e $72^{\circ} \mathrm{C}$ por 1 minuto) e extensão final a $72^{\circ} \mathrm{C}$ por 5 minutos.

Todas as reações foram realizadas no mesmo termociclador (C1000 thermal cycler, Bio-Rad Laboratories, Hercules, CA). Os produtos das PCRs foram submetidos a eletroforese em gel de agarose a $1,5 \%$, corados com brometo de etídio $(0,2 \mathrm{mg} / \mu \mathrm{L})$ e observados no transiluminador fluorescente (UV transilluminator ${ }^{\circledR}$, UVP LLC, Upland, CA). As seqüencias dos oligonucleotídeos utilizados, genes amplificados e tamanhos dos produtos da PCR estão apresentados no Quadro 1.

Em todas as PCRs foram utilizados como controles negativos água ultra pura miliQ (estéril e desprovida de DNA). Como controles positivos foram utilizadas amostras de DNA de E. canis, A. platys, A. phagocytophilum e Rickettsia spp. obtidas de animais naturalmente infectados, identificados por meio da microscopia óptica e/ou PCR e confirmados por meio do sequenciamento genético.

Os dados foram analisados utilizando o programa computacional estatístico (SPSS versão 9.0, de 2008). Para teste de normalidade utilizou-se Shapiro-Wilk. Para as variáveis que seguiram distribuição

Quadro 1. Descrição das sequências de oligonucleotídeos, alvos e tamanho dos produtos da PCR utilizados para detecção de agentes Rickettsiales

\begin{tabular}{|c|c|c|c|c|}
\hline Oligonucleotídeos & Sequência $\left(5^{\prime}-3^{\prime}\right)$ & Alvo & $\begin{array}{c}\text { Pares de } \\
\text { base }\end{array}$ & Referência \\
\hline GAPDH-R & CCT TCA TTG ACC TCA ACT ACA T & GAPDH & 400 & (Birkenheuer et al. 2003) \\
\hline GAPDH-F & CCA AAG TTG TCA TGG ATG ACC & & & \\
\hline $\operatorname{CS} 78$ & GCA AGT ATC GGT GAG GAT GTA AT & Família Rickettsiaceae & 401 & (Labruna et al. 2004) \\
\hline CS323 & GCT TCC TTA AAA TTC AAT AAA TCA GGA T & & & \\
\hline ECAN5 & CAA TTA TTT ATA GCC TCT GGC TAT AGG A & Ehrlichia canis & 398 & (Murphy et al. 1998) \\
\hline HE3 & TAT AGG TAC CGT CAT TAT CTT CCC TA & & & \\
\hline EHR16sr & GGT ACC YAC AGA AGA AGT CC & Anaplasma platys & 678 & (Inokuma et al. 2000) \\
\hline Platys & GAT TTT TGT CGT AGC TTG CTA TG & & & \\
\hline MSP3F & TGG TGG TGC GGG ATA TTT CTA TGT GCCC & Anaplasma & 179 & (Levin et al. 2002) \\
\hline MSP3R & ATT CCG AGG ATC AGG TGT G & phagocytophilum & & \\
\hline
\end{tabular}


normal foi realizado teste T e para as que não seguiam a distribuição normal foi realizado o teste Mann-Whitney U. Considerou-se o intervalo de confiança de 95\% para os dados hematológicos. Para análise de correlação entre os grupos e a origem ou sexo do animal, utilizou-se o Teste de Qui-quadrado. As diferenças foram consideradas significativas quando $\mathrm{p} \leq 0,05$.

\section{RESULTADOS}

Foram utilizadas para o experimento amostras de sangue de 34 felídeos cativos provenientes do ZOO (n=21) e do CC $(n=13)$. Esses animais eram de 9 espécies diferentes: 1 gato-do-mato (Leopardus tigrinus), 1 gato-maracajá (Leopardus wiedii), 3 gatospalheiro (Leopardus pajeros), 2 jaguarundis (Felis yagouaroundi), 2 jaguatiricas (Felis pardalis), 2 leões (Panthera leo), 11 onças (Panthera onca), 7 suçuaranas (Puma concolor) e 5 tigresde-bengala (Panthera tigris tigris). Dos animais utilizados, 15 eram fêmeas e 19 eram machos.

As trinta e quatro amostras testadas foram positivas na PCR para o gene GAPDH, apresentando um produto de $400 \mathrm{pb}$, denotando a qualidade do DNA utilizado e a ausência de inibidores da PCR (Fig.1A).

Nenhuma das amostras foi positiva para a família Rickettsiaceae (Fig.1B). Vinte e duas amostras (64,7\%) foram positivas na PCR para Anaplasma platys, onde foram observados produtos nos tamanhos de 678pb (Fig.1C). Dentre essas amostras positivas, dois $(5,88 \%)$ animais também foram positivos na PCR para E. canis (Fig.1D) e dois (5,88\%) animais também foram positivos para $A$. phagocytophilum (Fig.1E), sendo consideradas coinfecções (Quadro 2). Pode-se constatar uma elevada taxa de infecção por $A$. platys nos animais amostrados em relação aos demais agentes estudados.

Hemograma foi feito em apenas 24 amostras coletadas. A análise obteve médias, desvio padrão, limites inferiores e superiores com intervalo de confiança de 95\%. Na comparação dos valores entre os grupos, não houve diferença $(\mathrm{p}>0.05)$ entre os animais positivos e os animais negativos (Quadro 3). Contudo, merece destaque a análise individual dos hemogramas de dois animais, ambos positivos nas PCRs realizadas. 0 primeiro hemograma era de um gato maracajá, positivo para E. canis e
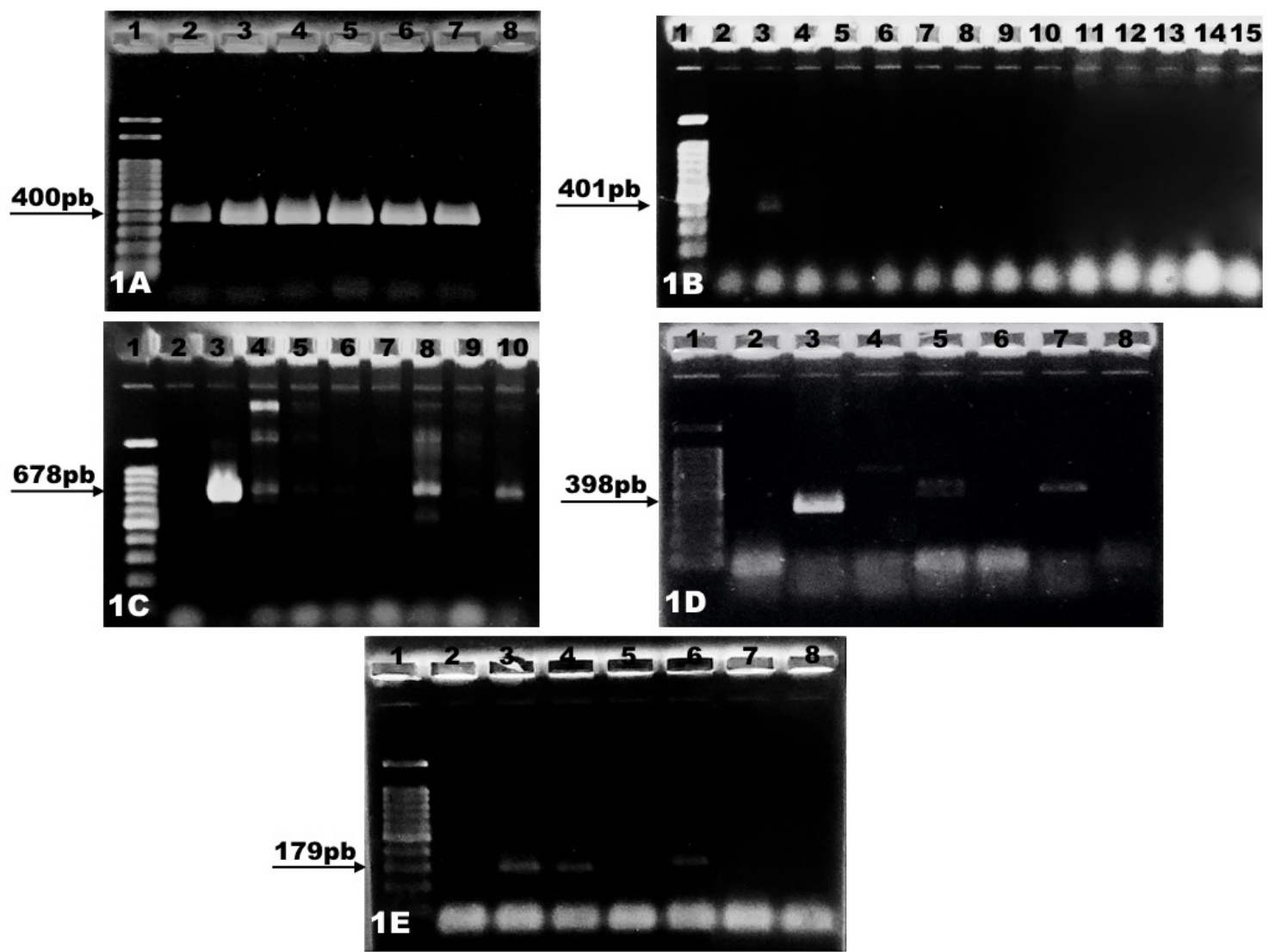

Fig.1. Eletroforese dos produtos da PCR utilizando diferentes oligonucleotídeos, em gel de agarose a 1,5\% (p/v) corado com brometo de etídeo a 0,01\% (p/v) para a detecção de DNA de agentes Rickettsiales em sangue de felídeos silvestres. (A) Amplificação do gene GAPDH (GAPDH-F e GAPDH-R, 400 pb), mostrando marcador de peso molecular (1), controle positivo (2), animais positivos (3-7), controle negativo (água) (8). (B) Detecção de DNA da família Rickettsiaceae (CS78 e CS323, 401 pb), mostrando marcador de peso molecular (1), controle negativo (água) (2), controle positivo (3), animais negativos (4-15). (C) Detecção de DNA de Anaplasma platys (EHR16sr e Platys, 678pb), mostrando marcador de peso molecular (1), controle negativo (água) (2), controle positivo (3), animais positivos (4-10), animais negativos (11-15). (D) Detecção de DNA de Ehrlichia canis (ECAN5 e HE3, 398pb), mostrando marcador de peso molecular (1), controle negativo (água) (2), controle positivo (3), animais positivos (5, 7), animais negativos (4, 6, 8). (E) Detecção de DNA de Anaplasma phagocytophilum (MSP3-R e MSP3-F, 179pb), mostrando marcador de peso molecular (1), controle negativo (água) (2), controle positivo (3), animais positivos (5, 7), animais negativos $(4,6,8)$. 
Quadro 2. Resultados obtidos nas PCR de amostras de sangue de felídeos silvestres provenientes do zoológico (Z00) e de um centro conservacionista de animais selvagens (CC)

\begin{tabular}{|c|c|c|c|c|c|c|c|}
\hline Identificação & Espécie & Local & Sexo & $\begin{array}{l}\text { Ehrlichia } \\
\text { canis }\end{array}$ & $\begin{array}{l}\text { Anaplasma } \\
\text { platys }\end{array}$ & $\begin{array}{c}\text { Anaplasma } \\
\text { phagocytophilum }\end{array}$ & Rickettsia spp. \\
\hline GJ & $\begin{array}{c}\text { Gato Maracajá (Leopardus } \\
\text { wiedii) }\end{array}$ & $\mathrm{ZOO}$ & M & + & + & - & - \\
\hline GM & $\begin{array}{l}\text { Gato do Mato Pequeno } \\
\text { (Leopardus tigrinus) }\end{array}$ & ZOO & M & - & + & - & - \\
\hline GP01 & $\begin{array}{l}\text { Gato Palheiro } \\
\text { (Leopardus pajerus) }\end{array}$ & $\mathrm{CC}$ & M & - & + & - & - \\
\hline GP02 & $\begin{array}{l}\text { Gato Palheiro } \\
\text { (Leopardus pajerus) }\end{array}$ & ZOO & M & - & + & - & - \\
\hline GP03 & $\begin{array}{l}\text { Gato Palheiro } \\
\text { (Leopardus pajerus) }\end{array}$ & ZOO & M & - & + & - & - \\
\hline JD01 & $\begin{array}{c}\text { Jaguarundi } \\
\text { (Puma yagouaroundi) }\end{array}$ & ZOO & $\mathrm{F}$ & - & - & - & - \\
\hline JD02 & $\begin{array}{c}\text { Jaguarundí } \\
\text { (Puma yagouaroundi) }\end{array}$ & ZOO & M & - & + & - & - \\
\hline $\mathrm{JG} 02$ & $\begin{array}{l}\text { Jaguatirica } \\
\text { (Leopardus pardalis) }\end{array}$ & $\mathrm{CC}$ & M & - & + & - & - \\
\hline L01 & $\begin{array}{l}\text { Leão Africano } \\
\text { (Panthera leo) }\end{array}$ & ZOO & M & - & + & - & - \\
\hline L02 & $\begin{array}{l}\text { Leão Africano } \\
\text { (Panthera leo) }\end{array}$ & ZOO & M & - & + & - & - \\
\hline OP01 & $\begin{array}{l}\text { Onça Pintada } \\
\text { (Panthera onca) }\end{array}$ & $\mathrm{ZOO}$ & $\mathrm{F}$ & - & + & - & - \\
\hline OP02 & $\begin{array}{l}\text { Onça Pintada } \\
\text { (Panthera onca) }\end{array}$ & $\mathrm{ZOO}$ & $\mathrm{F}$ & - & + & - & - \\
\hline OP03 & $\begin{array}{l}\text { Onça Pintada } \\
\text { (Panthera onca) }\end{array}$ & $\mathrm{CC}$ & M & - & - & - & - \\
\hline OP04 & $\begin{array}{l}\text { Onça Pintada } \\
\text { (Panthera onca) }\end{array}$ & $\mathrm{CC}$ & M & - & - & - & - \\
\hline OP05 & $\begin{array}{l}\text { Onça Pintada } \\
\text { (Panthera onca) }\end{array}$ & $\mathrm{CC}$ & M & - & + & - & - \\
\hline OP06 & $\begin{array}{l}\text { Onça Pintada } \\
\text { (Panthera onca) }\end{array}$ & $\mathrm{CC}$ & $\mathrm{F}$ & - & + & - & - \\
\hline OP07 & $\begin{array}{l}\text { Onça Pintada } \\
\text { (Panthera onca) }\end{array}$ & ZOO & M & - & - & - & - \\
\hline OP08 & $\begin{array}{l}\text { Onça Pintada } \\
\text { (Panthera onca) }\end{array}$ & $\mathrm{CC}$ & $\mathrm{F}$ & - & + & - & - \\
\hline OP09 & $\begin{array}{l}\text { Onça Pintada } \\
\text { (Panthera onca) }\end{array}$ & $\mathrm{CC}$ & $\mathrm{F}$ & - & + & - & - \\
\hline OP10 & $\begin{array}{l}\text { Onça Pintada } \\
\text { (Panthera onca) }\end{array}$ & $\mathrm{ZOO}$ & $\mathrm{F}$ & - & + & - & - \\
\hline SC01 & $\begin{array}{c}\text { Suçuarana } \\
\text { (Puma concolor) }\end{array}$ & ZOO & $\mathrm{F}$ & - & - & - & - \\
\hline $\mathrm{SC} 02$ & $\begin{array}{c}\text { Suçuarana } \\
\text { (Puma concolor) }\end{array}$ & ZOO & $\mathrm{F}$ & - & - & - & - \\
\hline SC03 & $\begin{array}{c}\text { Suçuarana } \\
\text { (Puma concolor) }\end{array}$ & $\mathrm{ZOO}$ & $\mathrm{F}$ & - & - & - & - \\
\hline SC04 & $\begin{array}{l}\text { Suçuarana } \\
\text { (Puma concolor) }\end{array}$ & $\mathrm{CC}$ & M & - & - & - & - \\
\hline SC05 & $\begin{array}{c}\text { Suçuarana } \\
\text { (Puma concolor) }\end{array}$ & $\mathrm{CC}$ & M & - & + & - & - \\
\hline SC06 & $\begin{array}{c}\text { Suçuarana } \\
\text { (Puma concolor) }\end{array}$ & $\mathrm{CC}$ & $\mathrm{F}$ & - & - & - & - \\
\hline SC07 & $\begin{array}{c}\text { Suçuarana } \\
\text { (Puma concolor) }\end{array}$ & CC & M & + & + & - & - \\
\hline ТВ01 & $\begin{array}{c}\text { Tigre de Bengala (Panthera } \\
\text { tigris) }\end{array}$ & $\mathrm{ZOO}$ & $\mathrm{F}$ & - & - & - & - \\
\hline TB02 & $\begin{array}{c}\text { Tigre de Bengala (Panthera } \\
\text { tigris) }\end{array}$ & $\mathrm{ZOO}$ & $\mathrm{F}$ & - & + & - & - \\
\hline ТВ03 & $\begin{array}{c}\text { Tigre de Bengala (Panthera } \\
\text { tigris) }\end{array}$ & ZOO & $\mathrm{F}$ & - & + & - & - \\
\hline TB04 & $\begin{array}{c}\text { Tigre de Bengala (Panthera } \\
\text { tigris) }\end{array}$ & $\mathrm{ZOO}$ & M & - & - & - & - \\
\hline TB05 & $\begin{array}{c}\text { Tigre de Bengala (Panthera } \\
\text { tigris) }\end{array}$ & ZOO & M & - & - & - & - \\
\hline JG01 & $\begin{array}{c}\text { Jaguatirica } \\
\text { (Leopardus pardalis) }\end{array}$ & ZOO & $\mathrm{F}$ & - & + & + & - \\
\hline OP11 & $\begin{array}{l}\text { Onça Pintada } \\
\text { (Panthera onca) }\end{array}$ & CC & M & - & + & + & - \\
\hline
\end{tabular}


Quadro 3. Média, desvio padrão e limites inferiores e superiores dos parâmetros hematológicos de felídeos silvestres cativos de DF e GO

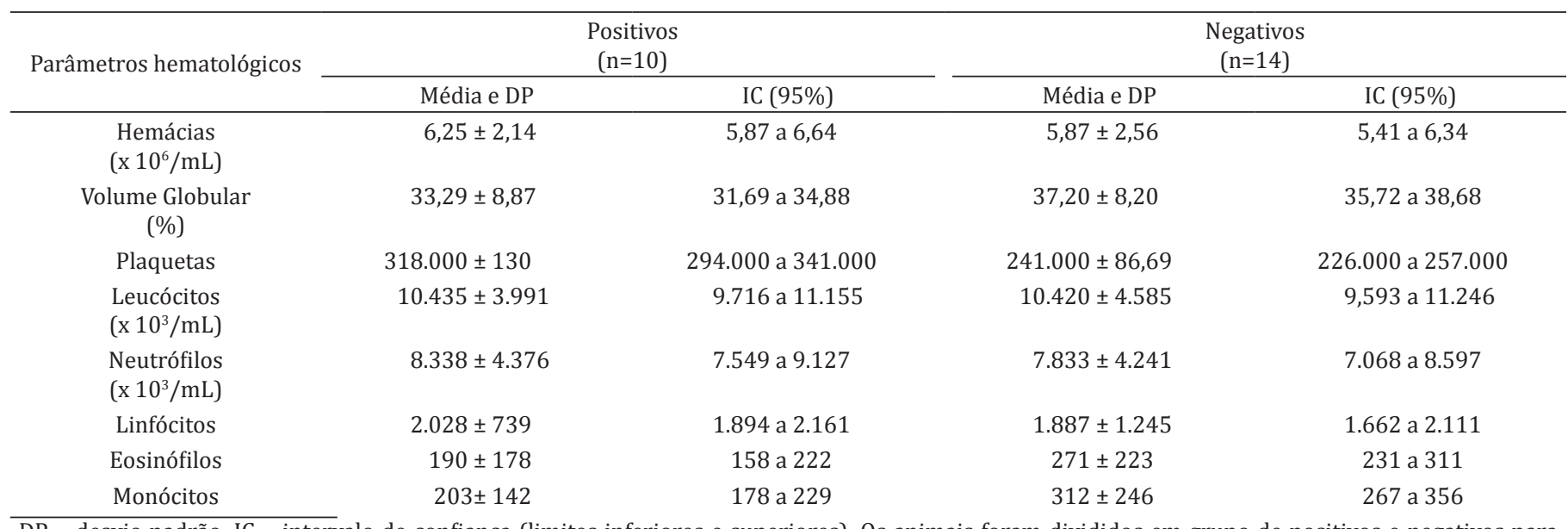

DP = desvio padrão, IC = intervalo de confiança (limites inferiores e superiores). Os animais foram divididos em grupo de positivos e negativos para agentes Rickettsiales, por meio da PCR. Não houve diferença significativa entre grupos para os valores das médias e de limites inferiores e superiores dos parâmetros hematológicos, considerando $\mathrm{p} \leq 0,05$, pelo teste T e Mann-Whitney U.

A. platys, cujo eritrograma apresentava uma severa anemia $\left(\mathrm{VG}=13 \%\right.$, hemácias $=2,44 \times 10^{6}$, hemoglobina $\left.=4,3 \mathrm{~g} / \mathrm{dL}\right)$. E o segundo hemograma de um gato palheiro, positivo para A. platys que apresentou trombocitopenia (plaquetas $=110.000 / \mu \mathrm{L}$ ). Na avaliação do esfregaço sanguíneo deste animal foi observada inclusão característica de mórula de $A$. platys em uma plaqueta. Todos os demais animais, positivos ou negativos apresentaram hemogramas dentro dos valores de referência para as espécies estudadas.

Utilizando o Teste do Qui-quadrado ao nível de significância de 5\%, não houve diferença significativa no número de animais positivos provenientes do ZOO e do CC, bem como também não houve diferença entre os sexos.

\section{DISCUSSÃO}

As doenças infeciosas transmitidas por vetores artrópodes são reemergentes em todo o mundo, devido às mudanças climáticas e ao acesso a outros nichos ecológicos que não os habituais, constituindo um grande desafio na medicina humana e veterinária. A proximidade entre os animais selvagens cativos, domésticos e humanos auxilia na transmissão de parasitas e amplia os potenciais reservatórios. Algumas espécies de Rickettsiales têm grande importância como causadores de doenças, tais como Ehrlichia canis, Anaplasma platys (Allison \& Little 2013), Rickettsia rickettsii (Labruna 2009, Fortes et al. 2011, Oliveira et al. 2017), R. parkerii, R. felis, R. typhi (Fortes et al. 2011) e A. phagocytophilum (Vieira et al. 2011). Entretanto, ainda não está estabelecido quais desses agentes ocorrem em felídeos silvestres, tampouco quais alterações hematológicas causariam nesses animais.

Em nenhuma das amostras de sangue obtidas foi amplificado DNA de Rickettsia spp. por meio da PCR. Os felídeos desse estudo vivem na região do cerrado brasileiro, ambiente com grande população de capivaras (Hydrochaeris hydrochaeris) e gambás (Didelphys sp.), que são hospedeiros amplificadores de riquétsias, assim como transportadores de carrapatos potencialmente infectados, principalmente
Amblyomma spp. Sabe-se, entretanto, que esse carrapato é encontrado principalmente no Sudeste do país, onde se concentra também a maioria de casos de Febre Maculosa Humana (Krawczak et al. 2014). Nos últimos 16 anos, apenas 8 casos da doença foram diagnosticados em G0 e 3 casos no DF, enquanto que no estado de São Paulo foram diagnosticados 813 casos (Brasil 2017). Outro aspecto a ser considerado é o desconhecimento acerca da patogenicidade de Rickettsias spp. para os felídeos silvestres ou se esses animais desenvolvem imunidade e são capazes de eliminá-las de seus organismos. Segundo Soares et al. (2015) esses agentes normalmente causam infecções transitórias em vertebrados, que duram apenas alguns dias, depois tornam-se imunorresistentes e não seria mais possível encontrar o DNA da Rickettsia no sangue do hospedeiro. 0 mesmo é passível de ocorrer nos felídeos silvestres. No presente estudo não foram realizados testes sorológicos para identificação de anticorpos para os agentes pesquisados, o que poderia ter auxiliado na avaliação da ocorrência ou não da infecção prévia com esses agentes na região. Widmer et al. (2011) encontraram anticorpos, mas não DNA, de espécies de Rickettsias em amostras de sangue de onças de vida livre do Pantanal. Em estudo com gatos domésticos, também foram encontradas amostras de sangue contendo anticorpos, mas nenhum DNA de Rickettsia foi identificado (Bayliss et al. 2009). Entretanto, Segura et al. (2014) encontraram soropositividade em $27.8 \%$ dos gatos estudados na Espanha e 10,8\% amostras positivas na PCR. Não se sabe, entretanto, se esses gatos estavam na fase aguda da infecção. A espécie de Rickettsia presente também pode influenciar no ciclo do agente no organismo dos hospedeiros, facilitando ou não a detecção de seu DNA em sangue periférico.

A presença de DNA de $A$. platys foi encontrada na maioria das amostras analisadas $(64,7 \%)$. A platys é um microrganismo que infecta plaquetas, resultando em inclusões basofílicas denominadas mórulas, que causa a doença denominada trombocitopenia cíclica canina (Allison \& Little 2013). Correa et al. (2011) investigaram a presença do DNA de A. platys em amostras de sangue de gatos domésticos em 
Campos do Goytacazes/RJ, sendo detectada em 13,18\% das amostras, sugerindo que gatos possam servir como potenciais reservatórios para esses agentes. Acredita-se que o mesmo possa ocorrer com os felídeos silvestres cativos que, talvez pelo convívio próximo com animais domésticos em algumas regiões, também se infectem com esses agentes tornando-se reservatórios.

A ocorrência de DNA de E. canis foi demostrada em $5,88 \%$ das amostras analisadas, resultado inferior ao encontrado por André et al. (2010), que obtiveram 15\% das amostras de felídeos silvestres cativos positivas. Em contrapartida, Widmer et al. (2011) realizaram um estudo com onças de vida livre do Pantanal e não encontraram nenhum animal positivo. Os animais positivos no presente estudo foram uma suçuarana e um gato-maracajá.

0 DNA de A. phagocytophilum foi encontrado em 5,88\% das amostras analisadas, resultado semelhante ao encontrado felídeos silvestres do zoológico de Sorocaba/SP, que foi de 4\% em gatos-do-mato (André et al. 2012). A presença de DNA de A. phagocytophilum também foi relatada em oito pumas nos EUA (Foley et al. 1999). A. phagocytophilum é o agente causal da zoonose ehrlichiose granulocítica humana (Vieira et al. 2011). No presente estudo, os animais positivos para A. phagocytophilum foram negativos para E. canis, entretanto havia coinfecção com A. platys.

Os dados hematológicos dos felídeos silvestres positivos para agentes Rickettsiales do presente estudo não foram significativamente diferentes dos dados encontrados no grupo de animais negativos, mesmo quando houve coinfecção. A análise individual dos hemogramas realizados revelou que um animal co-infectado com E. canis e A. platys apresentou anemia e outro infectado com A. platys apresentou trombocitopenia, entretanto, como não foram realizados outros exames clínico-laboratoriais para averiguar a existência de outras afecções concomitantes, não foi possível inferir que estas alterações tenham sido decorrentes da infecção por estes agentes. Ainda é incerto se A. platys seja capaz de causar doença clínica em felídeos silvestres e quais as alterações hematológicas decorrentes desta infecção. Em gatos domésticos alterações como anemia e trombocitopenia foram relatadas, porém, os animais apresentavam outras doenças concomitantes (Hegarty et al. 2015). E. canis é o agente etiológico da erliquiose canina no Brasil, doença que se apresenta desde uma infecção inaparente até casos que levam ao óbito. A bactéria infecta leucócitos mononucleares, podendo causar alterações hematológicas como trombocitopenia, pancitopenia e linfocitose. Em gatos domésticos, já foi documentada a infecção natural e experimental por Ehrlichia spp. (Almosny 1998, Little 2010, Ebani \& Bertelloni 2014, Maia et al. 2014) e assume-se que as alterações clínicas e laboratoriais nessa espécie sejam semelhantes às que ocorrem em cães (Almosny 1998, Little 2010, Braga et al. 2013). Braga et al. (2013) encontraram anemia, trombocitopenia e linfopenia nos gatos positivos na PCR para E. canis. Em felídeos silvestres, é incerto se essas bactérias causam alterações hematológicas. A. phagocytophilum já foi documentado em gatos domésticos causando anemia e trombocitopenia em animais doentes (Adaszek et al. 2013), entretanto, nenhum estudo havia sido realizado em silvestres.

\section{CONCLUSÕES}

0 presente trabalho identificou a ocorrência da infecção por Anaplasma Platys, Ehrlichia canis e A. phagocytophilum em felídeos selvagens, o que sugere que estes animais podem servir como potenciais reservatórios destes agentes para humanos e outros animais.

Estudos futuros, com um número maior de animais, principalmente de vida livre, devem ser realizados no intuito de avaliar se estes microrganismos são capazes de ocasionar alterações clínicas e hematológicas nos felinos selvagens.

Agradecimentos.- À Coordenação de Aperfeiçoamento de Pessoal de Nível Superior (CAPES), a Fundação de Empreendimentos Científicos e Tecnológicos (FINATEC) e ao Conselho Nacional de Pesquisa (CNPq) pelo suporte financeiro. À Fundação Zoológico de Brasília e ao Centro Conservacionista por disponibilizarem os animais e o pessoal para a obtenção das amostras de sangue.

\section{REFERÊNCIAS}

Adaszek Ł., Gorna M., Skrzypczak M., Buczek K., Balicki I. \& Winiarczyk S. 2013. Three clinical cases of Anaplasma phagocytophilum infection in cats in Poland. J. Feline Med. Surg. 15(4):333-337. http://dx.doi. org/10.1177/1098612X12466552. PMid:23143840.

Allison R.W. \& Little S.E. 2013. Diagnosis of rickettsial diseases in dogs and cats. Vet. Clin. Pathol. 42(2):127-144. http://dx.doi.org/10.1111/ vcp.12040. PMid:23647393.

Almeida A.P., Cunha L.M., Bello A.C., Cunha A.P., Domingues L.N., Leite R.C. \& Labruna M.B. 2011. A novel Rickettsia infecting Amblyomma dubitatum ticks in Brazil. Ticks Tick Borne Dis. 2(4):209-212. http://dx.doi.org/10.1016/j. ttbdis.2011.08.003. PMid:22108014.

Almosny N.R.P. 1998. Ehrlichia canis (Donatien \& Lestoquard 1935): avaliação parasitológica, hematológica e bioquímica sérica da fase aguda de cães e gatos experimentalmente infectados. Tese de Doutorado, Instituto de Biologia, Universidade Federal Rural do Rio de Janeiro, Seropédia, RJ. 224p.

André M.R., Adania C.H., Machado R.Z., Allegretti S.M., Felippe P.A., Silva K.F. \& Nakaghi A.C. 2010. Molecular and serologic detection of Ehrlichia spp. in endagered Brazilian wild captive felids. J. Wildl. Dis. 46(3):1017-1023. http://dx.doi.org/10.7589/0090-3558-46.3.1017. PMid:20688716.

André M.R., Dumler J.S., Scorpio D.G., Teixeira R.H., Allegretti S.M. \& Machado R.Z. 2012. Molecular detection of tick-borne bacterial agents in Brazilian and exotic captive carnivores. Ticks Tick Borne Dis. 3(4):247-253. http:// dx.doi.org/10.1016/j.ttbdis.2012.04.002. PMid:22749737.

Bayliss D.B., Morris A.K., Horta M.C., Labruna M.B., Radecki S.V., Hawley J.R., Brewer M.M. \& Lappin M.R. 2009. Prevalence of Rickettsia species antibodies and Rickettsia species DNA in the blood of cats with and without fever. J. Feline Med. Surg. 11(4):266-270. http://dx.doi.org/10.1016/j. jfms.2008.06.007. PMid:18786845.

Birkenheuer A.J., Levy M.G. \& Breitschwerdt E.B. 2003. Development and evaluation of a seminested PCR for detection and differentiation of Babesia gibsoni (Asian Genotype) and B. canis DNA in canine blood samples. J. Clin. Microbiol. 41(9):4172-4177. http://dx.doi.org/10.1128/JCM.41.9.41724177.2003. PMid:12958243.

Braga I.A., Santos L.G., Melo A.L., Jaune F.W., Ziliani T.F., Girardi A.F. \& Aguiar D.M. 2013. Hematological values associated to the serological and molecular diagnostic in cats suspected of Ehrlichia canis infection. Revta Bras. Parasitol. Vet. 22(4):470-474. http://dx.doi.org/10.1590/S198429612013000400005 . PMid:24473870.

Brasil 2017. Casos Febre Maculosa 2000 a 2017. Ministério da Saúde, Disponível em <http://portalarquivos2.saude.gov.br/images/pdf/2017/ setembro/14/Casos-de-febre-maculosa.pdf> 
Coimbra H.S., Fernandes C.G., Soares M.P., Meireles M.C.A., Radamés R. \& Schuch L.F.D. 2006. Ehrlichiose monocítica eqüina no Rio Grande do Sul: aspectos clínicos, anátomo-patológicos e epidemiológicos. Pesq. Vet. Bras. 26(2):97-101. http://dx.doi.org/10.1590/S0100-736X2006000200006.

Correa E.S., Paludo G.R., Scalon M.C., Machado J.A., Lima A.C.Q., Pinto A.T.B., Thiebaut J.T.L. \& Albernaz A.P. 2011. Investigação molecular de Ehrlichia spp. e Anaplasma platys em felinos domésticos: alterações clínicas, hematológicas e bioquímicas. Pesq. Vet. Bras. 31(10):899-909. http:// dx.doi.org/10.1590/S0100-736X2011001000011.

Dumler J.S., Barbet A.F., Bekker C.P.J., Dasch G.A., Palmer G.H., Ray S.C., Rikihisa Y. \& Rurangirwa F.R. 2001. Reorganization of genera in the families Rickettsiaceae and Anaplasmataceae in the order Rickettsiales: unification of some species of Ehrlichia with Anaplasma, Cowdria with Ehrlichia and Ehrlichia with Neorickettsia, descriptions of six new species combinations and designation of Ehrlichia equi and 'HGE agent' as subjective synonyms of Ehrlichia phagocytophila. Int. J. Syst. Evol. Microbiol. 51(Pt 6):21452165. http://dx.doi.org/10.1099/00207713-51-6-2145. PMid:11760958.

Ebani V.V. \& Bertelloni F. 2014. Serological evidence of exposure to Ehrlichia canis and Anaplasma phagocytophilum in Central Italian healthy domestic cats. Ticks Tick Borne Dis. 5(6):668-671. http://dx.doi.org/10.1016/j. ttbdis.2014.04.019. PMid:25113987.

Filoni C., Catão-Dias J.L., Bay G., Durigon E.L., Jorge R.S.P., Lutz H. \& HofmannLehmann R. 2006. Fist evidence of feline herpesvirus, calicivirus, parvovirus and ehrlichia exposure in Brazilian free-ranging felids. J. Wildl. Dis. 42(2):470477. http://dx.doi.org/10.7589/0090-3558-42.2.470. PMid:16870878.

Foley J.E., Foley P., Jecker M., Swift P.K. \& Madigan J.E. 1999. Granulocitic ehrlichiosis and thick infestation in mountais lions in California. J. Wildl. Dis. 35(4):703-709. http://dx.doi.org/10.7589/0090-3558-35.4.703. PMid:10574529.

Fortes F.S., Santos L.C., Cubas Z.S., Barros-Filho I.R., Biondo A.W., Silveira I., Labruna M.B. \& Molento M.B. 2011. Anti-Rickettsia spp. antibodies in free-ranging and captive capybaras from souther Brazil. Pesq. Vet. Bras. 31(11):1014-1018. http://dx.doi.org/10.1590/S0100-736X2011001100013.

Fournier P.-E. \& Raoult D. 2007. Bacteriology, taxonomy, and phylogeny of rickettsia, p.1-15. In: Parola P. (Ed.), Rickettsial Diseases. Informa Helthcare, London. http://dx.doi.org/10.3109/9781420019971.001.

Hegarty B.C., Qurollo B.A., Thomas B., Park K., Chandrashekar R., Beall M.J., Thatcher B. \& Breitschwerdt E.B. 2015. Serological and molecular analysis of feline vector-borne anaplasmosis and ehrlichiosis using species-specific peptides and PCR. Parasit. Vectors 8(1):320. http://dx.doi.org/10.1186/ s13071-015-0929-8. PMid:26062723.

Inokuma H., Raoult D. \& Brouqui P. 2000. Detection of Ehrlichia platys DNA in Brown Dog Ticks (Rhipicephalus sanguineus) in Okinawa Island, Japan. J. Clin. Microbiol. 38(11):4219-4221. PMid:11060094.

Krawczak F.S., Nieri-Bastos F.A., Nunes F.P., Soares J.F., Moraes-Filho J. \& Labruna M.B. 2014. Rickettsial infection in Amblyomma cajennense ticks and capybaras (Hydrochoerus hydrochaeris) in a Brazilian spotted feverendemic area. Parasit. Vectors 7(7):7. http://dx.doi.org/10.1186/17563305-7-7. PMid:24387674.

Labruna M.B. 2009. Ecology of rickettsia in South America. Ann. N.Y. Acad. Sci. 1166(1):156-166. http://dx.doi.org/10.1111/j.1749-6632.2009.04516.x. PMid:19538276.

Labruna M.B., Whitworth T., Horta M.C., Bouyer D.H., McBride J.W., Pinter A., Popov V., Gennari S.M. \& Walker D.H. 2004. Rickettsia species infecting Amblyomma cooperi ticks from an area in the state of Sao Paulo, Brazil, where Brazilian Spotted Fever is endemic. J. Clin. Microbiol. 42(1):90-98. http://dx.doi.org/10.1128/JCM.42.1.90-98.2004. PMid:14715737.

Labruna M.B., Mattar S., Nava S., Bermudez S., Vazal J.M., Dolz G., Abarca K., Romero L., Sousa R., Oteo J. \& Zavala-Castro J. 2011. Rickettsioses in Latin
America, Caribbean, Spain and Portugal. Revta MVZ Cordoba 16(2):24352457. http://dx.doi.org/10.21897/rmvz.282.

Larsen R.S., Kreeger T.J., West G., Heard D. \& Caulkett N. 2008. Canids, p.395407. In: Larsen R.S., Heard D. \& Caulkett N. (Eds), Zoo Animal and Wildlife Immobilization and Anesthesia. Blackwell Publishing Ltd, New Jersey.

Levin M.L., Nicholson W.L., Massung R.F., Sumner J.W. \& Fish D. 2002. Comparison of the reservoir competence of medium-sized mammals and Peromyscus leucopus for Anaplasma phagocytophilum in Connecticut. Vector Borne Zoonotic Dis. 2(3):125-136. http://dx.doi.org/10.1089/15303660260613693. PMid:12737542.

Little S.E. 2010. Ehrlichiosis and anaplasmosis in dogs and cats. Vet. Clin. N. Am., Small Anim. Pract. 40(6):1121-1140. PMid:20933140.

Maia C., Ramos C., Coimbra M., Bastos F., Martins A., Pinto P., Nunes M., Vieira M.L., Cardoso L. \& Campino L. 2014. Bacterial and protozoal agents of feline vector-borne diseases in domestic and stray cats from southern Portugal. Parasit. Vectors 7(115):115. http://dx.doi.org/10.1186/17563305-7-115. PMid:24655431.

Murphy G.L., Ewing S.A., Whitworth L.C., Fox J.C. \& Kocan A.A. 1998. A molecular and serologic survey of Ehrlichia canis, E. chaffensis, and E. ewingii in dogs ticks from Oklahoma. Vet. Parasitol. 79(4):325-339. http://dx.doi. org/10.1016/S0304-4017(98)00179-4. PMid:9831955.

Oliveira C.S., Bräunig P., Krawczak F., Labruna M.B., Botton S.A., Vogel F.S.F. \& Sangioni L.A. 2017. Detecção de proteínas imunorreativas de Rickettsia sp. cepa Mata Atlântica. Pesq. Vet. Bras. 37(1):52-57.http://dx.doi.org/10.1590/ s0100-736x2017000100009.

Parola P., Paddock C.D., Socolovschi C., Labruna M.B., Mediannikov O., Kernif T., Abdad M.Y., Stenos J., Bitam I., Fournier P.E. \& Raoult D. 2013. Update on tick-borne rickettsioses around the world: a geographic approach. Clin. Microbiol. Rev. 26(4):657-702. http://dx.doi.org/10.1128/CMR.00104-13. PMid:24092850.

Picoloto G., Lima R.F., Olegário L.A., Carvalho C.M., Lacerda A.C., Tomás W.M., Borges P.A., Pellegrin A.O. \& Madruga C.R. 2010. Real time polymerase chain reaction to diagnose Anaplasma marginale in cattle and deer (Ozotoceros bezoarticus leucogaster) of the Brazilian Pantanal. Revta Bras. Parasitol. Vet. 19(3):186-188. http://dx.doi.org/10.1590/S1984-29612010000300012. PMid:20943025.

Sacchi A.B., Duarte J.M., André M.R. \& Machado R.Z. 2012. Prevalence and molecular characterization of Anaplasmataceae agents in free-ranging Brazilian marsh deer (Blastocerus dichotomus). Comp. Immunol. Microbiol Infect. Dis. 35(4):325-334. http://dx.doi.org/10.1016/j.cimid.2012.02.001. PMid:22381686.

Segura F., Pons I., Miret J., Pla J., Ortuño A. \& Nogueras M.M. 2014. The role of cats in the eco-epidemiology of spotted fever group diseases. Parasit. Vectors 7:353. PMid:25084969.

Soares H.S., Barbieri A.R., Martins T.F., Minervino A.H., de Lima J.T., Marcili A., Gennari S.M. \& Labruna M.B. M.B. 2015. Ticks and rickettsial infection in the wildlife of two regions of the Brazilian Amazon. Exp. Appl. Acarol. 65(1):125140. http://dx.doi.org/10.1007/s10493-014-9851-6. PMid:25273064.

Vieira R.F., Biondo A.W., Guimarães A.M., Santos A.P., Santos R.P., Dutra L.H., Diniz P.P., Morais H.A., Messick J.B., Labruna M.B. \& Vidotto O. 2011. Ehrlichiosis in Brazil. Revta Bras. Parasitol. Vet. 20(1):1-12. http://dx.doi. org/10.1590/S1984-29612011000100002. PMid:21439224.

Widmer C.E., Azevedo F.C.C., Almeida A.P., Ferreira F. \& Labruna M.B. 2011. Tick-borne bacteria in free-living jaguars (Panthera onca) in Pantanal, Brazil. Vector Borne Zoonotic Dis. 11(8):1001-1005. http://dx.doi.org/10.1089/ vbz.2011.0619. PMid:21612532. 